\title{
Preparation and physico-chemical characterization of matrix pellets containing APIs with different solubility via extrusion process
}

\author{
Diána Hegyesi, Markus Thommes, Peter Kleinebudde, Tamás Sovány, Péter \\ Kása Jr., András Kelemen, Klára Pintye-Hódi \& Géza Regdon Jr.
}

To cite this article: Diána Hegyesi, Markus Thommes, Peter Kleinebudde, Tamás Sovány, Péter Kása Jr., András Kelemen, Klára Pintye-Hódi \& Géza Regdon Jr. (2016): Preparation and physico-chemical characterization of matrix pellets containing APIs with different solubility via extrusion process, Drug Development and Industrial Pharmacy, DOI: 10.1080/03639045.2016.1261150

To link to this article: http://dx.doi.org/10.1080/03639045.2016.1261150

Accepted author version posted online: 14 Nov 2016.

Submit your article to this journal ¿

a)

View related articles $₫$

View Crossmark data $\nearrow$ 


\section{Preparation and physico-chemical characterization of matrix pellets containing APIs with different solubility via extrusion process}

Diána Hegyesi $^{1,2}$, Markus Thommes ${ }^{3}$, Peter Kleinebudde ${ }^{4}$, Tamás Sovány ${ }^{1}$, Péter Kása Jr. ${ }^{5}$, András Kelemen ${ }^{6}$, Klára Pintye-Hódi ${ }^{1}$, Géza Regdon Jr. ${ }^{1 *}$

1 Institute of Pharmaceutical Technology and Regulatory Affairs, University of Szeged, Eötvös utca 6., H-6720 Szeged, Hungary

2 Gedeon Richter Ltd. Gyömröi út 19-21., H-1103, Budapest, Hungary

3 Department of Biochemical and Chemical Engineering, Chair of Solids Process Engineering, Technical University Dortmund, Emil-Figge-Street 68, D-44227 Dortmund, Germany

4 Institute of Pharmaceutics and Biopharmaceutics, Heinrich Heine University, Universitätsstraße 1., Geb. 26.22, D-40225 Düsseldorf, Germany

5 Evonik Nutrition \& Care GmbH Magyarországi Fióktelepe, Városligeti fasor 44. 1068 Budapest Hungary

6 Department of Applied Informatics, University of Szeged, Boldogasszony sgt. 6., $\mathrm{H}$ 6720 Szeged, Hungary

* e-mail: geza.regdon@pharm.u-szeged.hu

* Corresponding author: dr. habil. Géza Regdon jr. PhD, Associate professor Department of Pharmaceutical Technology, University of Szeged

Eötvös u. 6., H-6720, Szeged, Hungary

Telephone: +3662545574

Fax: +36 62545571

E-mail: geza.regdon@pharm.u-szeged.hu 


\title{
Preparation and physico-chemical characterization of matrix pellets containing APIs with different solubility via extrusion process
}

\begin{abstract}
In this study a multiparticulate matrix system was produced, containing two different APIs: enalapril-maleate and hydrochlorothiazide. The critical control points of the process were investigated by means of factorial design. Besides the generally used microcrystalline cellulose, ethylcellulose was used as matrix former to achieve modified drug release ensured by diffusion. The matrix pellets were made by extrusion-spheronization using a twin-screw extruder. Some pellet properties (aspect ratio, 10\% interval fraction, hardness, deformation process) were determined. The aim of our study was to investigate how the two different APIs with different solubility and particle size influence the process. The amount of the granulation liquid plays a key role in the pellet shaping. A higher liquid feed rate is preferred in the pelletization process.
\end{abstract}

Keywords: enalapril-maleate, hydrochlorothiazide, multiparticulate matrix system, extrusion, spheronization, pellets 


\section{Introduction}

Enalapril-maleate is an ACE (angiotensin converting enzyme) inhibitor agent used in the treatment of hypertension. It reduces RAS (renin-angiotensin system) activity in the body, and has cardioprotective and renal-protective effects [1]. It is also used to treat congestive heart failure in adults. This API belongs to Class III of the Biopharmaceutics Classification System (BCS), so it has low permeability and high solubility. The absorption is limited by the permeation rate but the drug dissolves fast. The side effects of the API include allergic reactions, high potassium blood level (hyperkalaemia), dizziness, abdominal pain. To reduce these side effects, enalapril-maleate is often combined with diuretics, which reduces the potassium level in blood.

Hydrochlorothiazide is a thiazide diuretic medication often used to treat high blood pressure. This API belongs to BCS Class IV, it has low permeability and low solubility. Those compounds have poor bioavailability. Usually they are not well absorbed over the intestinal mucosa and a high variability is expected.

This work focused on the extrusion-spheronization process. The process of extrusion is applied in the pharmaceutical industry to manufacture many types of dosage forms. The strands of extrudates must not adhere to each other, and must exhibit such plasticity that the shape imposed by the die is maintained. In case of spheronization, under ideal circumstances, almost sphere-shaped particles are obtained. Drying follows spheronization.

Microcrystalline cellulose (MCC) may be regarded as the standard and the most commonly used matrix former material in pellet preparation with extrusion [2-4]. It has plastic properties, thus it provides the cohesiveness of the wetted mass, which is suitable for extrusion and spheronization. MCC has a large surface area and high internal porosity, therefore it introduces the liquid into the matrix. Furthermore, in consequence 
of its large surface area and high internal porosity, it is able to absorb and retain a large quantity of water thereby facilitating extrusion, improving the wetted mass plasticity and enhancing spheronization [5-8]. Moreover, the control of the movement of water through the plastic mass prevents phase separation during extrusion or spheronization. In order to decrease the amount of the used MCC, other pharmaceutical excipients are added and can achieve modified drug release, e.g. hydroxypropyl methylcellulose (HPMC) and hydroxyethyl cellulose (HEC) [9], ethylcellulose (EC) [7, 10], or Kcarrageenan $[11,12]$.

EC is an ideal polymer for the formation of products allowing modified drug release. It is insoluble at any $\mathrm{pH}$ level that occurs in the living organism, but in the presence of gastric juice it undergoes swelling. It is then permeable for water and permits extended drug release.

This makes it suitable to improve patient compliance with the use of preparations administered once/twice daily [13]. A small number of ethylcellulose polymers have been approved for general pharmaceutical application (Ethocel 4, Ethocel 10, Ethocel 45 etc.), which only differ in the length of polymer chains, and in the rate of dissolution and the viscosity of their solution $[14,15]$ and are used in extended release solid dosage formulations. These ethylcelluloses are usually used as coating materials in the preparation of multiparticulate dosage forms $[16,17]$, but in recent studies EC is also used as matrix former excipient, especially in hot-melt extrusion processes, due to its excellent thermoplastic properties [18]. The application of EC in wet extrusion processes is limited, since the polymer has considerable elastic properties, but can be successfully used as matrix former in combination with some plasticizing agents $[19,20]$. Mallipeddi et al. used the potential of coarse ethylcellulose (CPEC) and fine particle ethylcellulose (FPEC) as diluent with high molecular weight 
polyethylene oxide (PEO), which was used as an extrusion aid and a binder [19, 20]. Their results have shown that water is sufficient to prepare a wet granulation product when using FPEC. MCC was included in their formulations to contribute its plasticity to the wetted mass during extrusion and to the extrudate during spheronization.

In this work FPEC was used as matrix former, $\mathrm{MCC}$ as pelletization aid and deionised water with ethanol and TEC as granulation liquid.

The present study is focusing on the optimization of the mechanical properties of EC-MCC sustained release matrix pellets, to understand the effect of the incorporated APIs with different solubility and particle size on the texture and mechanics of these systems.

\section{Materials and methods}

\section{Materials}

Enalapril-maleate (EM) and hydrochlorothiazide (HCT) (Richter Gedeon Ltd., Budapest, Hungary) were applied as active pharmaceutical ingredient (API). Ethocel Standard 10 FP Premium (Colorcon Ltd. Dartford. England) was used as matrix former and MCC type 101 (Avicel 101, FMC Corporation, Philadelphia, USA) as pharmaceutical excipient (pelletization aid). A mixture from $1 \%$ triethyl-citrate (TEC), in an aqueous ethanol solution $96 \%(\mathrm{~V} / \mathrm{V})$ and deionised water were used as granulation liquid. 


\section{Methods}

\section{Experimental plan}

The study dealt with the effect of 3 process parameters - spheronization time $\left(\mathrm{x}_{1}\right)$, the liquid feed rate $\left(\mathrm{x}_{2}\right)$, and the speed of the friction plate $\left(\mathrm{x}_{3}\right)$ - on the pellet properties (shape, tensile strength, breaking force). Mixed 2 and 3 level factorial design was applied to optimize the process parameters and the best composition for the experiments. We examined the liquid feed rate $\left(\mathrm{x}_{2}\right)$ and the speed of the friction plate $\left(x_{3}\right)$ on 3 levels, while the effect of spheronization time on 2 levels. These dependent variables influenced the properties of the pellets. Statistica for Windows 11 AGA (Statsoft. Inc. Tulsa. USA) software was applied to determine the effects of the factors.

\section{Preparation of pellets}

1500 grams of powder mixture was prepared from $20 \%$ of API (enalapril-maleate or hydrochlorothiazide), $30 \%$ of ethylcellulose and $50 \%$ of microcrystalline cellulose.

The powders were combined in a laboratory-scale blender (LM40, Bohle, Ennigerloh, Germany) for $10 \mathrm{~min}$ at $25 \mathrm{rpm}$ and then transferred into the gravimetric powder feeder (KT 20, K-Tron Soder, Lenzhard, Switzerland) of the extruder. The twin-screw extruder (Mikro 27GL-28D, Leistritz, Nuremberg, Germany) was equipped with an axial screen with 23 dies of $1 \mathrm{~mm}$ diameter and $5 \mathrm{~mm}$ length. The extrusion took place at a constant screw speed of $100 \mathrm{rpm}$, a powder feed rate of $33 \mathrm{~g} / \mathrm{min}$ and a liquid feed rate according to the experimental plan. Deionised water (89\%) and $96 \%$ ethanol (10\%) with TEC (1\%) were used as granulation liquid supplied by a membrane pump. Batches of $40 \mathrm{~g}$ resultant strands of extrudates were collected and spheronized in a spheronizer (Caleva 120, Sturminster Newton, UK) according to the design of 
experiments. The particles were dried in a fluid bed apparatus (GPCG 1.1., Glatt, Dresden, Germany) for 20 min with an inlet air temperature of $60^{\circ} \mathrm{C}$.

\section{Image Analyzer}

The shape of the pellets was studied with image analysis using a system consisting of a stereo microscope (Leica MZ 75, Cambridge, UK), a ringlight with cold light source (Leica KL 1500, Cambridge, UK), a digital camera (Leica CS 300 F, Cambridge, UK), and an image analyzing software (Qwin, Leica, Cambridge, UK). In case of APIs, the particle size was analysed with the use of SEM images by Image J 1.46r (National Institute of Health, USA, http://imagej.nih.gov) software.

The images of at least 500 pellets of each sample at a suitable magnification were translated into binary images. Contacting pellets were separated by a software algorithm. For each pellet, 36 Feret diameters were determined and also used to calculate the mean Feret diameter. The ratio of the maximum Feret diameter and the Feret diameter perpendicular to the maximum Feret diameter is used as the aspect ratio (AR). The pellet size and shape were characterized by the mean Feret diameter, aspect ratio and $10 \%$ interval, respectively (Eq.1)

$$
d=\frac{\mathrm{d}_{\mathrm{F}}}{\mathrm{d}_{\mathrm{F} 50}}
$$

with the dimensionless diameter $(\mathrm{d})$, mean Feret diameter $\left(\mathrm{d}_{\mathrm{F}}\right)$ and median of all mean Feret diameters $\left(\mathrm{d}_{\mathrm{F} 50}\right)$.

The roundness of the particles is calculated with the following equation (Eq.2):

$$
\mathrm{O}=4 \frac{\mathrm{A}}{\pi \mathrm{d}_{\mathrm{Fmax}}{ }^{2}}
$$


where $\circ$ is the roundness of the particles, $A$ is the area, and $d_{F m a x}$ is the maximal Feret diameter.

The distribution of the particle size is characterized by the fraction of the particles in the interval $0.9<\mathrm{d}<1.1$. The size distribution is characterized as good if the fraction of the $10 \%$ interval exceeds $50 \%$ and as excellent if it exceeds $75 \%$.

\section{Scanning electron microscope}

The surfaces and the structures were tested with a scanning electron microscope (SEM) (Hitachi S4700, Hitachi Scientific Instruments Ltd., Tokyo, Japan). A sputter coating unit (Polaron E5100, VG Microtech, UK) was used to charge the surfaces for the SEM measurements. The air pressure during the analyses was $1.3-13 \mathrm{mPa}$.

Mechanical properties of pellets

The breaking strength of 40 pellets was tested. The strength tester and the software were developed in our institute in Szeged. The technical parameters are as follows: range of measurement: 0-200 N, rate of displacement: $20 \mathrm{~mm} / \mathrm{min}$, registering output: 0-500 $\mathrm{mV}$, force sensor: Unicell load cell (C9B $20 \mathrm{kN}$ cell). By changing the pressure jowl (stamp) and the sample holder, the equipment is appropriate for the measurement of the crushing force $(\mathrm{F})$ of pellets. The breaking strength (hardness) value is given by the force of the last peak of the force-time plot, corresponding to the complete breaking of the pellet. 


\section{Results and discussion}

Both active ingredients (APIs) have tabular crystal habit (Fig. 1) and heterodisperse size distribution (Table 1). The most considerable difference between the APIs is particle size. EM crystals are tenfold bigger than hydrochlorothiazide particles. A further difference is that whilst EM crystals are well-developed and sometimes covered by tiny, irregularly-shaped crystal grains (Fig. 1a), the edges and corners of the HCT crystals are rounded (Fig. 1d, e, f). The sticking of smaller particles on the surface of larger crystals - which suggests a strong cohesion between them - is also characteristic of HCT. That is why a number of irregular looking crystals are visible at small magnifications (Fig. 1b), with the presence of some big crystal agglomerates. It is well visible at higher magnifications (Fig. 1d, e, f) that the smaller particles are irregular aggregates of few tabular crystals, while bigger agglomerates are formed from undeveloped particles (Fig. 1c) and behave as individual units in the product.

As it can be seen, except for the solubility and particle size, the general physical properties of the APIs are similar, and their mechanical behaviour during the extrusionspheronization process is expected to be similar, too.

Pellets are defined as spherical, free flowing granules with a narrow size distribution, typically varying between 0.50 and $1.50 \mathrm{~mm}$. All experimental settings resulted in pellets for both formulations with a mean average Feret diameter from 1.0 to $1.5 \mathrm{~mm}$ (Table 2). The shorter spheronization time results in larger size particles. The reason for this phenomenon is that the particles do not have enough time to get a rounded shape, and thus "bone" shaped particles are formed during spheronization, the particle size of which is larger as well. The $10 \%$ interval describes the fraction of pellets within the interval $0.9-1.1$ of the dimensionless diameter. The fraction in the $10 \%$ interval was in the 50-94\% range in case of pellets with enalapril-maleate and in the 52- 
97\% range in case of hydrochlorothiazide pellets. Thus all size distributions can be regarded as good.

The most common parameter to describe the shape of pellets is the aspect ratio. Pellets of a mean aspect ratio above 1.2 were regarded insufficient [21].

The results show that the aspect ratio and the other shape parameters are the worst if the process parameters are at minimum level (Fig. 2a), but spherical-shaped pellets may be gained with some optimization. The aspect ratio was close to 1 in the case of Samples 16-18 for both APIs, where the liquid feed rate and the spheronization time is on a higher level (Fig. 2b).

The effect of the different process parameters as factors was studied on the basis of a mixed (2 and 3) level full factorial design. The different experimental settings and the corresponding physical properties are displayed in Table 2.

The response surfaces of the various optimization parameters may be described with the following general equation 3. :

$$
y=b_{0}+b_{1} x_{1}+b_{2} x_{2}+b_{22} x_{2}^{2}+b_{3} x_{3}+b_{33} x_{3}{ }^{2}+b_{12} x_{1} x_{2}+b_{13} x_{1} x_{3}+b_{23} x_{2} x_{3}
$$

(where $\mathrm{x}_{1}$ :spheronization time, $\mathrm{x}_{2}$ :liquid feed rate, $\mathrm{x}_{3}$ : spheronization speed)

The regression coefficients and statistical results are displayed in Table 3, significant factors are highlighted with red colour.

It can be seen from the statistical results that the aspect ratio is significantly influenced by all three factors, within standard 95\% CI $(\mathrm{p}<0.05)$ and the liquid feed rate $\left(\mathrm{x}_{2}\right)$ has the most considerable effect, while spheronization time $\left(\mathrm{x}_{1}\right)$ has the smallest, for both APIs. The higher factor values resulted in smaller aspect ratio values and also in the formation of sphere-shaped pellets in both cases. Nevertheless, a considerable difference between the two APIs is that the aspect ratio of HCT pellets decreases 
linearly with the increment of the liquid addition rate, while EM exhibits a nonlinear dependence on this factor (Fig. 3a, b). The explanation of this difference may be the different solubility of the APIs, which exerts considerable effect on the pellet texture through the influencing of the distribution of the water inside the wet mass.

The structural differences of the samples are well visible on the cross-sectional scanning electron micrographs (Fig. 4). Although the low magnification images show compact spongiform texture for all investigated samples, the pellets with higher aspect ratio (Fig. 4a, b) exhibit slightly higher apparent porosity, while pellets with low AR show a dense texture, despite the hole in their centre (Fig. 4e, f). The increasing magnification reveals some differences of the sponge-like texture of the EC-MCC matrices. Besides the smooth surface of the embedded EM crystals surrounded with fibriform, filamentous, crumpled MCC grains (black arrows), numerous rounded EC particles (red arrows) connected to them may be clearly identified in EM 1 pellets (Fig. 4c). The cross section of HCT-1 pellets shows more uneven surface, but the general matrix texture is similar and the round EC grains (red arrows) may be identified (Fig. 4d). It can be assumed that the smaller crystals are bound to the matrix formers with a greater force. The cross-sectional picture shows that the matrix-former breaks up in a filamentous way, so cohesion was strong there. The breaking surface of the EM-18 and HCT-18 pellets (Fig. 4e, f) is generally splintered, which indicates strong cohesion between the particles. Numerous fibrous ruptures (white arrows) may be identified on the breaking surface, which can be due to the elastic deformation of the EC grains during the breaking process (Fig. 4g, h). Consequently, intact, rounded EC grains cannot be identified in EM 18 and HCT 18 pellets. This indicates that the high liquid feed rate induced structural (morphological) changes in the EC grains, and the better deformation of these samples may be due to the plasticizing effect of the water. 
If the better soluble EM bonds more water, that could be the reason for the nonlinear relation between the aspect ratio and liquid addition rate in these pellets.

The differences of the two APIs are also visible if we take into consideration the interactions between the factors. In the case of EM pellets, the interaction of the spheronization speed and the liquid feed rate is significant, and the other interactions have a negligible effect. In contrast, the interaction of the liquid feed rate with the two spheronization parameters has equal weight for HCT pellets. In general, the spheronization speed has almost no effect on the shape of the particles at low liquid feed rates, which also supports the negative effect of the unplasticized EC grains on this parameter.

The different texture and embedding mechanism of the API crystals also have a significant effect on the mechanical properties (hardness) of pellets. The general breaking process of the pellets is displayed in Figure 5. Each section of the process is marked by a coloured line. The deformation of a pellet starts with a short period of elastic deformation. The green line shows the maximum value of this period. In the second stage, a short period of viscoelastic deformation occurs, which can be due to the presence and elastic properties of EC (from green line to black). The third stage involves the first cracks in the pellet (from black line to purple), influencing only the microstructure without any sign of macroscopic changes. In the fourth stage, as pressure increases, a structure change develops in the pellet (from purple line to red). Every solid body-bridge within the pellet will crack in this stage. In the end (from the red line), the final deformation of the pellet occurs.

Cespi et al. states [22] that various authors adopted different approaches to assume the correspondence between a given peak of such a complicated deformation procedure and the real crushing strength value. In some cases, the last one was chosen, 
whereas in other cases the highest one and yet in other works the first peak giving a preset drop of force was taken into account. In the present case the breaking hardness value is given by the force corresponding to the last peak of the force-time plot, since this was the starting point of the macroscopic deformation of the pellets.

The maximal breaking strength of HCT pellets is lower in comparison with the corresponding EM ones (Table 2), possibly due to the different embedding and distribution of API particles within the EC-MCC matrix. Furthermore, the statistical analysis revealed that although the pellet hardness is influenced most significantly by spheronization time, within 95\% CI $(\mathrm{p}<0.05)$ for both APIs, but amongst the other factors the liquid feed rate is significant for the EM and the spheronization speed for the HCT pellets (Table 3). This indicates the different behaviour of the various textures, which may be related to the different number and arrangement of solid bridges inside the matrix. The greater hardness of EM pellets is possibly related to the greater amount of dissolved particles due to the better solubility of the API, which results in more intense solid bridge formation after the drying and recrystallization of these particles.

\section{Conclusions}

It was confirmed that the assurance of required pellet shape is problematic due to the elastic properties of EC. The use of EC-MCC mixture provides better process yield in comparison with the EC-MCC-PEO mixture applied by Mallipeddi et. al, since there is no hydrogel formation.

The amount of the granulation liquid plays a key role in the pellet shaping. The higher liquid addition rate induced morphological changes in the EC grains. At the same time the wet mass had a higher plasticity, which resulted in better densification and 
deformability within the studied factor space.

The solubility of the applied API also has a considerable effect on the pellet properties. As it was expected, similar shape parameters may be ensured using lower liquid addition rates if well soluble API is granulated. Nevertheless, the decrease of the liquid addition rate below a certain level has a negative effect on the liquid distribution, which results in a nonlinear relationship between liquid addition rate and aspect ratio.

\section{Disclosure statement}

The authors declare that they have no conflicts of interest to disclose.

\section{Funding information}

We would like to thank Richter Gedeon Ltd., and Colorcon Ltd and FMC Corporation for providing the active agent and the excipients, and special thanks to Gedeon Richter Ltd., who supported the experimental work in Düsseldorf. 


\section{References}

[1] Aygen B, Kucuksu M, Aydin S, Ozercan IH. (2015). Effect of enalapril-maleate on ghrelin levels in metabolic syndrome in rats. Peptides, 67:39-44.

[2] Koester M, Thommes M. (2013). Analysis of particle kinematics in spheronization via particle image velocimetry. Eur J Pharm Biopharm, 83:307-314.

[3] Alves-Silva I, Marreto RN, Gelfuso GM, Sá-Barreto LCL, Lima E, Filho MC. (2016). Preparation of benznidazole pellets for immediate drug delivery using the extrusion spheronization technique. Drug Dev Ind Pharm, DOI: $10.1080 / 03639045.2016 .1220574$

[4] Goyanes A, Martinez-Pacheco R. (2015). New co-processed MCC-based excipient for fast release of low solubility drugs from pellets prepared by extrusionspheronization. Drug Dev Ind Pharm, 41:362-368.

[5] Sonaglio D, Bataille B, Ortigosa C, Jacob M. (1995). Factorial design in the feasibility of producing Microcel MC 101 pellets by extrusion/spheronization. Int J Pharm, 115:53-60.

[6] Dukic-Ott A, Thommes M, Kleinebudde P, Vervaet C. (2009). Production of pellets via extrusion-spheronisation without the incorporation of microcrystalline cellulose: A critical review. Eur J Pharm Biopharm, 71:38-46.

[7] Hamedelniel EI, Bajdik J, Pintye-Hódi K. (2010). Optimization of preparation of matrix pellets containing ethylcellulose. Chem Eng Process, 49:120-124. 
[8] Bölcskei É, Regdon G jr, Sovány T, Kleinebudde P, Pintye-Hódi K. (2012). Optimization of preparation of matrix pellets containing Eudragit ${ }^{\circledR} \mathrm{NE} 30 \mathrm{D}$. Chem Eng Res Des, 90:651-657.

[9] Chatlapalli R, Rohera BD. (1998). Physical characterization of HPMC and HEC and investigation of their use as pelletization aids. Int J Pharm, 161:179-193.

[10] Hamedelniel EI, Bajdik J, Kása P jr, Pintye-Hódi K. (2012). Study of the influence of alkalizing components on matrix pellets prepared by extrusion/spheronization. Pharm Dev Techn, 17:2004-2011.

[11] Thommes M, Kleinebudde P. (2006). Use of K-carrageenan as alternative pelletisation aid to microcrystalline cellulose in extrusion/spheronisation. I. Influence of type and fraction filler. Eur J Pharm Biopharm, 63:59-67.

[12] Thommes M, Kleinebudde P. (2006). Use of K-carrageenan as alternative pelletisation aid to microcrystalline cellulose in extrusion/spheronisation. II. Influence of drug and filler type. Eur J Pharm Biopharm, 63:68-75.

[13] Claxton AJ, Cramer J, Pierce C. (2001). A systematic review of the associations between dose regiments and medication compliance. Clin Ther, 23:1296-1310.

[14] Hegyesi D, Sovány T, Pintye-Hódi K, Regdon G jr. (2013). Study of effect of plasticizer on the structure and surface characteristics of ethylcellulose free films with FT-IR spectroscopy. Microchem J, 110:36-39.

[15] Hegyesi D, Süvegh K, Kelemen A, Pintye-Hódi K, Regdon G jr. (2014). Characterisation of ethylcellulose free films by positron annihilation spectroscopy and mechanical tests. Microchem J, 115:47-50. 
[16] Tang ESK, Chan LW, Heng PWS. (2005). Coating of multiparticulates for sustained release. Am J Drug Deliv, 3:17-28.

[17] Liu Y, Sun Y, Jin SJ, Zhao N, Sun M, He Z. (2012). Preparation and in vitro/in vivo evaluation of sustained-release venlafaxine hydrochloride pellets. Int J Pharm, 426:21-28.

[18] Vynckier AK, Dierickx L, Saerens L, Voorspoels J, Gonnissen Y, De Beer T, Vervaet C, Remon JP. (2014). Hot-melt co-extrusion for the production of fixed-dose combination products with a controlled release ethylcellulose matrix core. Int J Pharm, 464:65-74.

[19] Mallipeddi R, Saripella KK, Neau SH. (2010). Use of coarse ethylcellulose and PEO in beads produced by extrusion-spheronization. Int J Pharm, 385:53-65.

[20] Mallipeddi R, Saripella KK, Neau SH. (2014). Use of fine particle ethylcellulose as the diluent in the production of pellets by extrusion-spheronization. Saudi Pharm J, 22:360-371.

[21] Kleinebudde P. (1995). Use of a power-consumption-controlled extruder in the development of pellet formulations. J Pharm Sci, 84:1259-1264.

[22] Cespi M, Bonacucina G, Misici-Falzi M, Golzi R, Boltri L, Palmieri GF. (2007). Stress relaxation test for the characterization of the viscoelasticity of pellets. Eur $\mathbf{J}$ Pharm Biopharm, 67:476-484. 


\section{Legend to Figures}

Figure 1. SEM picture of EM (a), and HCT in magnification 200x (b) 500x (aggregate) (c), $500 \mathrm{x}$ (individual crystals) (d), 1000x (e) and 2000x (f)

Figure 2. SEM pictures of insufficient (a) and well-shaped (b) pellets

Figure 3. Response surface on the aspect ratio of EM (a) and HCT (b), and hardness of EM (c) and HCT (d) pellets

Figure 4. Scanning electron micrographs of the cross sections of various pellets (EM 1 100x (a), HCT 1 100x (b), EM 1 1000x (c), HCT 1 1000x (d), EM 18 100x (e), HCT 18 100x (f), EM 18 1000x (g), HCT 18 1000x (h))

Figure 5. General deformation process of the studied pellets 

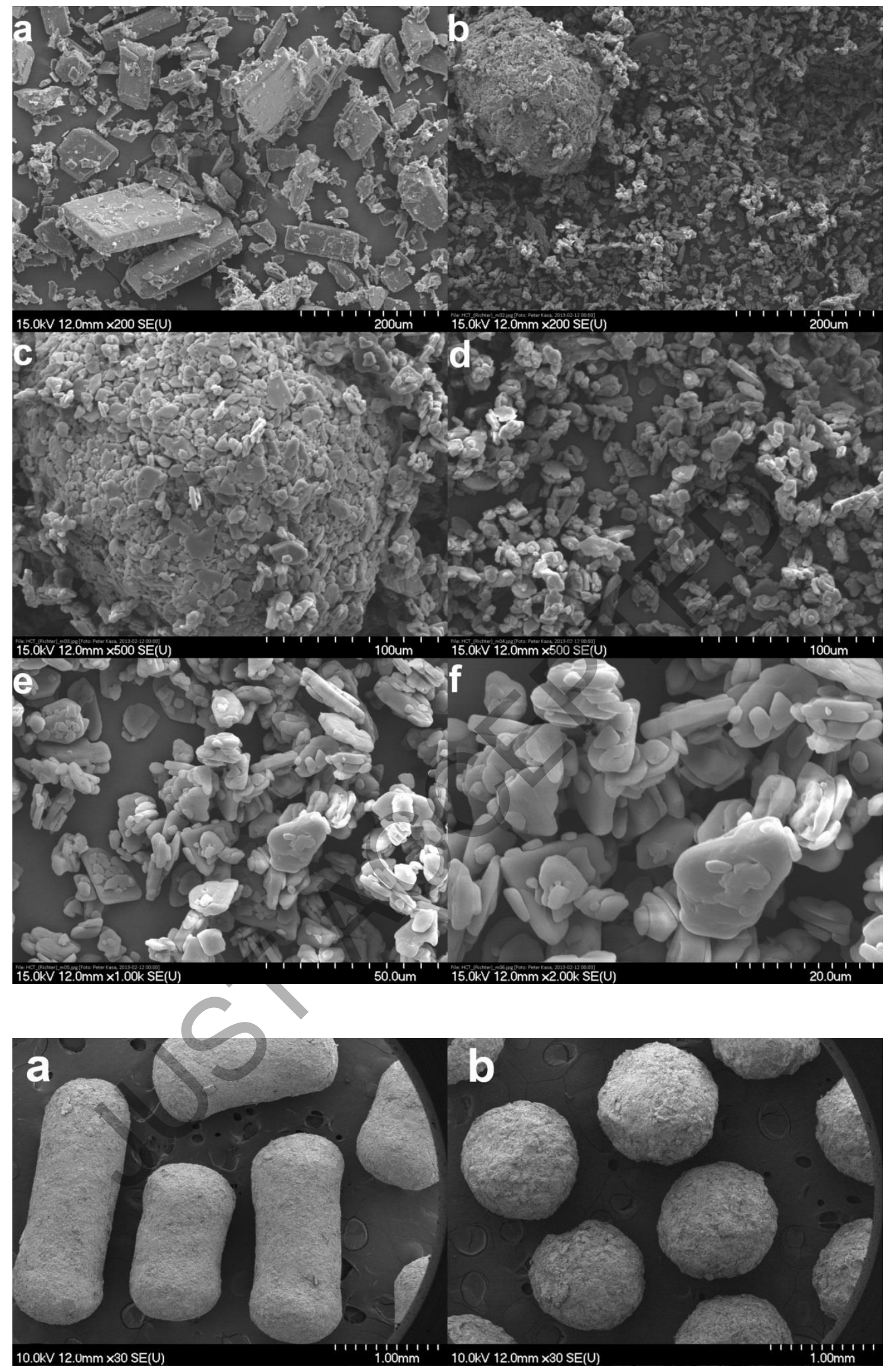


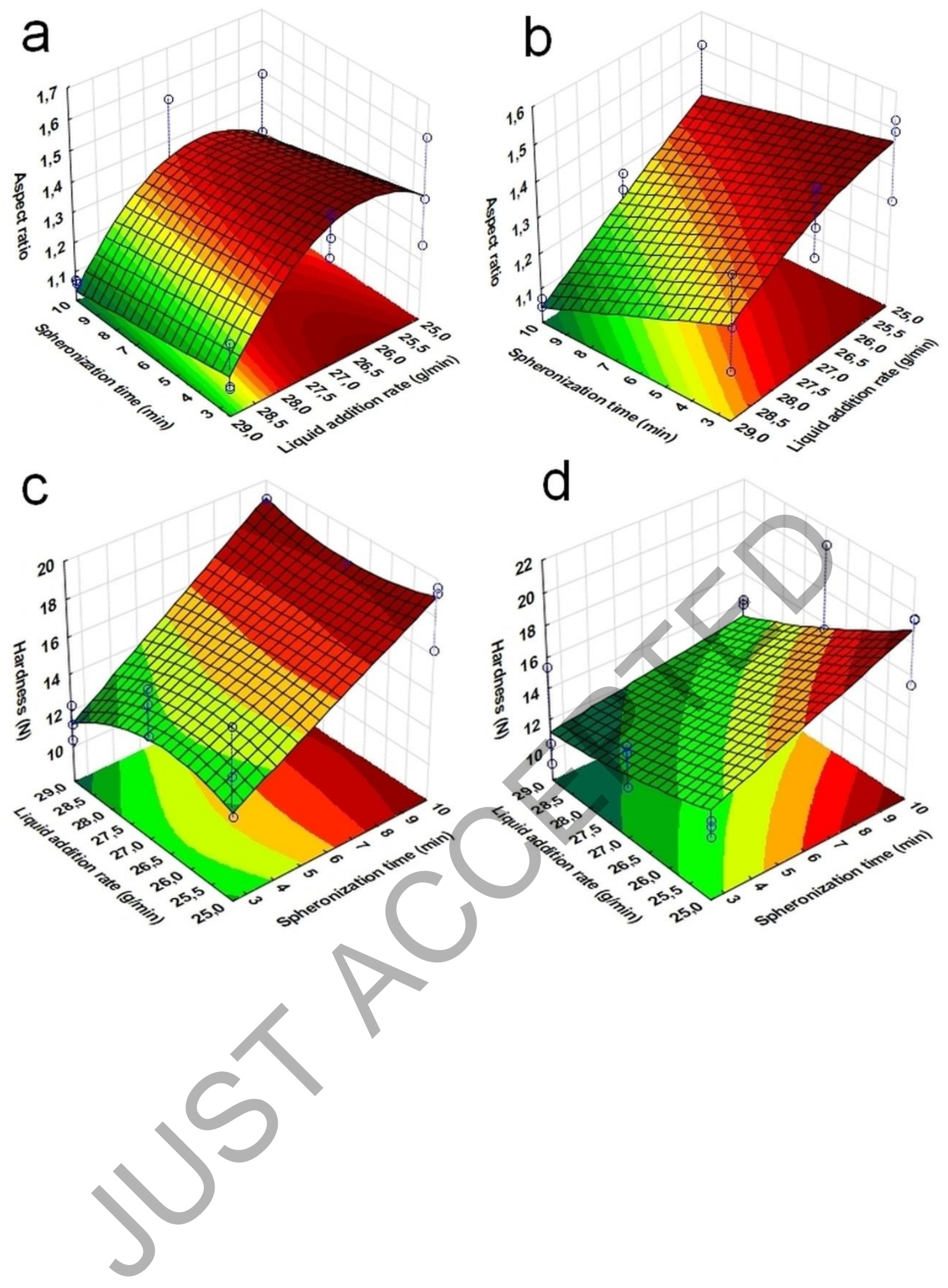




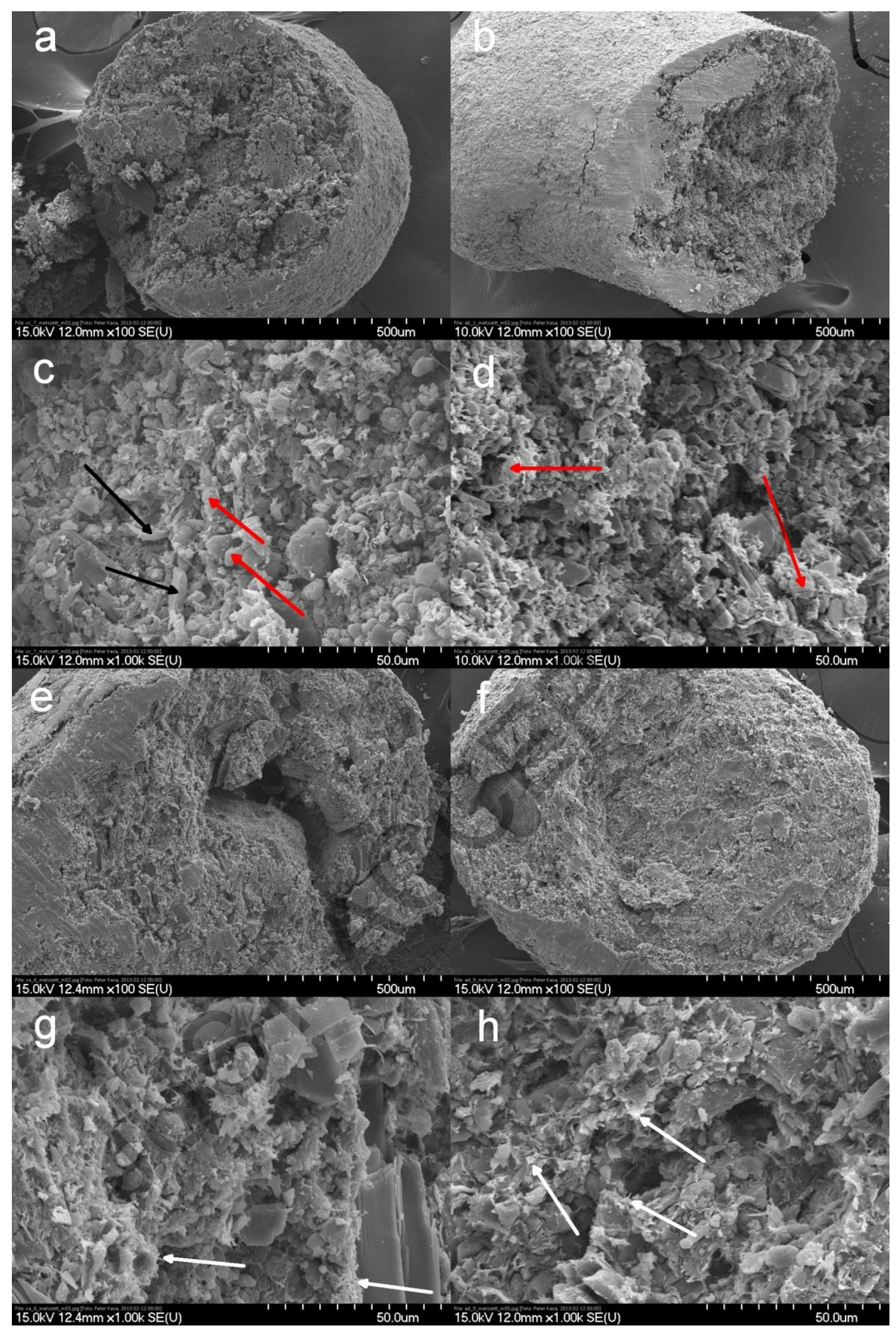




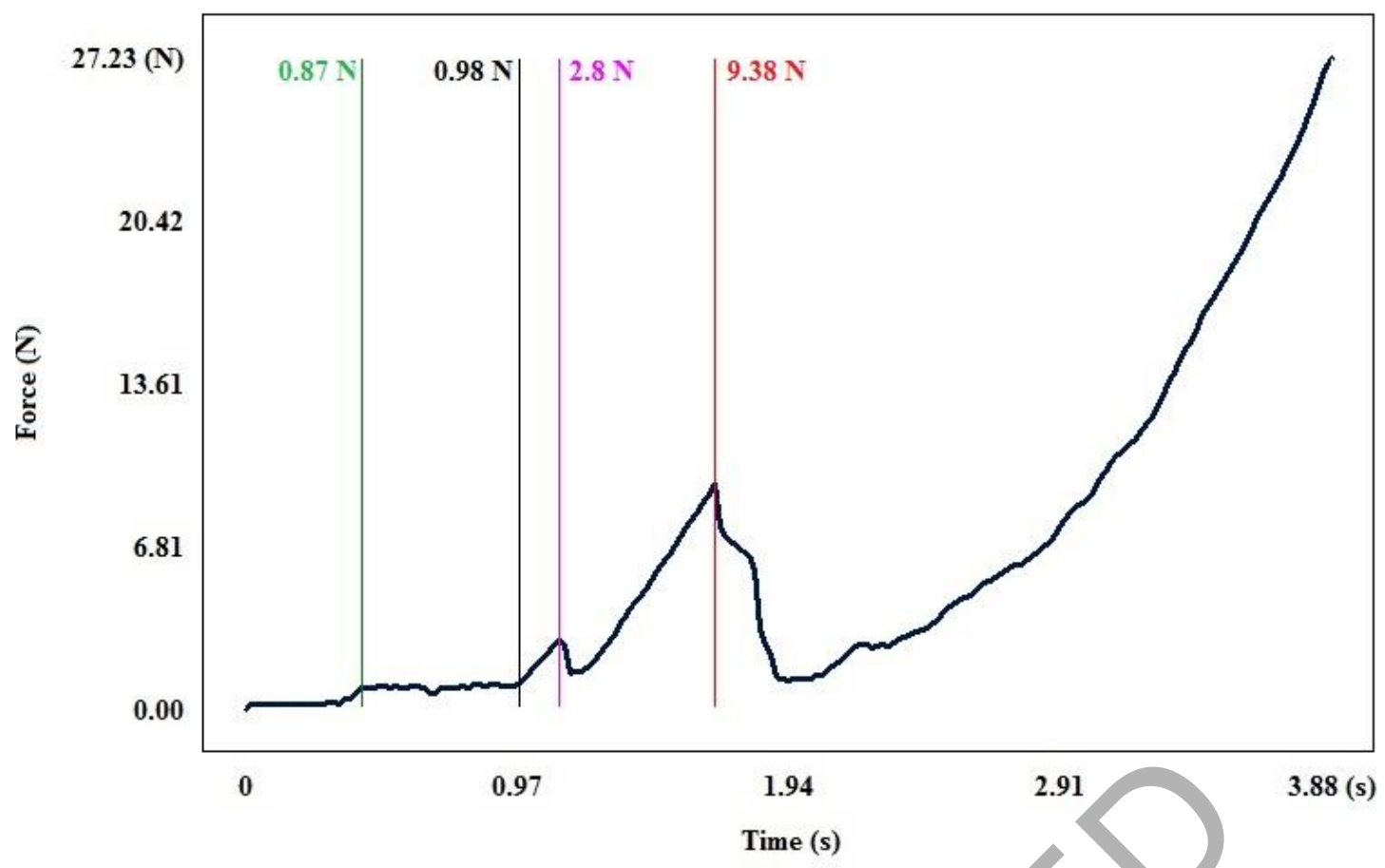

Table 1 - Morphological parameters of APIs

\begin{tabular}{|c|c|c|}
\hline & Enalapril-maleate & Hydrochlorothiazide \\
\hline Aspect ratio & 1.866 & 1.829 \\
\hline Roundness & 0.595 & 0.63 \\
\hline $\begin{array}{c}\text { Mean Feret diameter }(\mu \mathrm{m}) \\
\text { Aqueous solubility } \\
(\mathrm{mg} / \mathrm{ml})\end{array}$ & $67.4( \pm 43.84)$ & $5.57( \pm 3.96)$ \\
\hline
\end{tabular}


Table 2 - Properties of EM and HCT-containing pellets as a function of the production parameters

\begin{tabular}{|c|c|c|c|c|c|c|c|c|c|c|c|}
\hline \multirow{2}{*}{ Samples } & \multirow{2}{*}{$\begin{array}{c}X_{1} \\
\text { Spher } \\
\text { time } \\
(\text { min })\end{array}$} & \multirow{2}{*}{$\begin{array}{c}\mathrm{X}_{2} \\
\text { Liquid } \\
\text { feed rate } \\
\text { (g/min) } \\
\text { (EM/HCT) }\end{array}$} & \multirow{2}{*}{\begin{tabular}{|c|}
$X_{3}$ \\
Spher. \\
speed \\
$($ rpm)
\end{tabular}} & \multicolumn{2}{|c|}{$\begin{array}{c}\text { Mean Feret } \\
\text { diameter } \\
(\mathrm{mm})\end{array}$} & \multicolumn{2}{|c|}{$\begin{array}{c}10 \% \\
\text { interval (\%) }\end{array}$} & \multicolumn{2}{|c|}{ Aspect ratio } & \multicolumn{2}{|c|}{$\begin{array}{l}\text { Hardness } \\
(\mathbf{N})\end{array}$} \\
\hline & & & & EM & HCT & EM & HCT & EM & HCT & EM & HCT \\
\hline 1. & 2.5 & $25 / 26.3$ & 1000 & $\begin{array}{c}1.31 \\
( \pm 0.06)\end{array}$ & $\begin{array}{c}1.27 \\
( \pm 0.12)\end{array}$ & 52.8 & 52.2 & 1.60 & 1.58 & 17.3 & 12.0 \\
\hline 2. & 2.5 & $25 / 26.3$ & 1250 & $\begin{array}{c}1.21 \\
( \pm 0.08)\end{array}$ & $\begin{array}{c}1.46 \\
\pm 0.17)\end{array}$ & 62.4 & 70.0 & 1.40 & 1.52 & 12.6 & 13.0 \\
\hline 3. & 2.5 & $25 / 26.3$ & 1500 & $\begin{array}{c}1.13 \\
( \pm 0,09)\end{array}$ & $\begin{array}{c}1.15 \\
( \pm 0.09)\end{array}$ & 49.5 & 56.2 & 1.25 & 1.33 & 14.7 & 12.7 \\
\hline 4. & 2.5 & $27 / 28.5$ & 1000 & $\begin{array}{c}1.25 \\
( \pm 0.11)\end{array}$ & $\begin{array}{c}1.28 \\
( \pm 0.11)\end{array}$ & 50.8 & 59.6 & 1.57 & & 16.2 & 11.3 \\
\hline 5. & 2.5 & $27 / 28.5$ & 1250 & $\begin{array}{c}1.20 \\
( \pm 0.08)\end{array}$ & $\begin{array}{c}1.22 \\
( \pm 0.11)\end{array}$ & 73.8 & 60.6 & & & 13.7 & 13.5 \\
\hline 6. & 2.5 & $27 / 28.5$ & 1500 & $\begin{array}{c}1.23 \\
( \pm 0.10)\end{array}$ & $\begin{array}{c}1.16 \\
\pm 0.07)\end{array}$ & 76.8 & & 1.36 & 1.32 & 15.4 & 13.9 \\
\hline 7. & 2.5 & $29 / 30.3$ & 1000 & $\begin{array}{c}1.22 \\
( \pm 0.02)\end{array}$ & $\begin{array}{c}1.22 \\
( \pm 0.08)\end{array}$ & 82.6 & 66.4 & 1.24 & 1.44 & 10.4 & 9.1 \\
\hline 8. & 2.5 & $29 / 30.3$ & 1250 & $\begin{array}{c}1.25 \\
( \pm 0.11) \\
\end{array}$ & $\begin{array}{c}1.17 \\
( \pm 0.13)\end{array}$ & 79.6 & 77.6 & 1.10 & 1.27 & 11.2 & 10.4 \\
\hline 9. & 2.5 & $29 / 30.3$ & 1500 & $\begin{array}{c}1.12 \\
( \pm 0.14)\end{array}$ & $\begin{array}{c}1.16 \\
\pm 0.14)\end{array}$ & 85.0 & 73.4 & 1.10 & 1.16 & 12.3 & 15.4 \\
\hline 10. & 10 & $25 / 26.3$ & 1000 & $\begin{array}{c}1.22 \\
( \pm 0.07)\end{array}$ & $\begin{array}{c}1.22 \\
( \pm 0.10)\end{array}$ & 78.2 & 63.4 & 1.49 & 1.54 & 16.3 & 15.4 \\
\hline 11. & 10 & $25 / 26.3$ & 1250 & $\begin{array}{c}1.17 \\
( \pm 0.07)\end{array}$ & $\begin{array}{c}1.14 \\
( \pm 0.08)\end{array}$ & 93.6 & 82.6 & 1.30 & 1.36 & 19.3 & 19.5 \\
\hline 12. & 10 & $25 / 26.3$ & 1500 & $\begin{array}{c}1.10 \\
( \pm 0.11)\end{array}$ & $\begin{array}{c}1.01 \\
( \pm 0.07)\end{array}$ & 91.4 & 82.6 & 1.15 & 1.24 & 19.5 & 19.5 \\
\hline 13. & 10 & $27 / 28.5$ & 1000 & $\begin{array}{c}1.23 \\
( \pm 0.08)\end{array}$ & $\begin{array}{c}1.16 \\
( \pm 0.11)\end{array}$ & 87.2 & 85.2 & 1.54 & 1.30 & 15.2 & 15.6 \\
\hline 14. & 10 & $27 / 28.5$ & 1250 & $\begin{array}{c}1.17 \\
( \pm 0.14)\end{array}$ & $\begin{array}{c}1.13 \\
( \pm 0.10)\end{array}$ & 92.6 & 86.4 & 1.31 & 1.25 & 18.1 & 14.2 \\
\hline 15. & & $27 / 28.5$ & 1500 & $\begin{array}{c}1.11 \\
( \pm 0.12)\end{array}$ & $\begin{array}{c}1.03 \\
( \pm 0.09)\end{array}$ & 93.0 & 75.4 & 1.15 & 1.11 & 18.0 & 20.9 \\
\hline 16. & 10 & $29 / 30.3$ & 1000 & $\begin{array}{c}1.21 \\
( \pm 0.09) \\
\end{array}$ & $\begin{array}{c}1.19 \\
( \pm 0.13)\end{array}$ & 90.4 & 97.0 & 1.07 & 1.08 & 15.1 & 14.3 \\
\hline 17. & 10 & $29 / 30.3$ & 1250 & $\begin{array}{c}1.18 \\
( \pm 0.08) \\
\end{array}$ & $\begin{array}{c}1.10 \\
( \pm 0.12)\end{array}$ & 84.0 & 96.8 & 1.06 & 1.05 & 19.1 & 14.0 \\
\hline 18. & 10 & $29 / 30.3$ & 1500 & $\begin{array}{c}1.18 \\
( \pm 0.07)\end{array}$ & $\begin{array}{c}1.09 \\
( \pm 0.10)\end{array}$ & 82.0 & 95.6 & 1.07 & 1.06 & 15.1 & 14.0 \\
\hline
\end{tabular}


Table 3 - Effects of factors on the aspect ratio (AR) and breaking hardness

\begin{tabular}{|c|c|c|c|c|}
\hline & \multicolumn{2}{|c|}{ AR } & \multicolumn{2}{c|}{ Hardness } \\
\hline & EM & HCT & EM & HCT \\
\hline $\mathbf{R}^{2}$ & 0.9215 & 0.9525 & 0.7070 & 0.7996 \\
\hline MS Residual & 0.0047 & 0.0023 & 4.1575 & 3.6379 \\
\hline $\mathbf{b}_{\mathbf{0}}$ & 1.283 & 1.285 & 15.515 & 14.370 \\
\hline $\mathbf{b}_{\mathbf{1}}$ & -0.047 & -0.080 & 1.764 & 2.002 \\
\hline $\mathbf{b}_{\mathbf{2}}$ & -0.129 & -0.117 & -1.373 & -1.237 \\
\hline $\mathbf{b}_{\mathbf{2 2}}$ & 0.071 & 0.007 & 0.434 & 0.413 \\
\hline $\mathbf{b}_{\mathbf{3}}$ & -0.107 & -0.099 & 0.381 & 1.561 \\
\hline $\mathbf{b}_{\mathbf{3 3}}$ & -0.004 & 0.005 & 0.104 & -0.204 \\
\hline $\mathbf{b}_{\mathbf{1}} \mathbf{b}_{\mathbf{2}}$ & 0.008 & -0.031 & 0.398 & -0.782 \\
\hline $\mathbf{b}_{\mathbf{1}} \mathbf{b}_{\mathbf{3}}$ & -0.014 & 0.014 & 0.623 & -0.039 \\
\hline $\mathbf{b}_{\mathbf{2}} \mathbf{b}_{\mathbf{3}}$ & 0.069 & 0.030 & 0.154 & 0.153 \\
\hline
\end{tabular}

